\title{
Communication
}

\section{Remote Sensing time series to evaluate direct land use change of recent expanded sugarcane crop in Brazil}

\author{
Marcos Adami ${ }^{1}{ }^{*}$, Bernardo F.T. Rudorff ${ }^{1}$, Ramon M. Freitas ${ }^{1}$, Daniel A. Aguiar ${ }^{1}$, Marcio \\ Pupin Mello ${ }^{1}$ \\ ${ }^{1}$ National Institute for Space Research, Avenida dos Astronautas, 1758, São José dos Campos, SP, \\ 12243-750, Brazil.
}

E-Mails: bernardo@dsr.inpe.br (B.R.); ramon@dsr.inpe.br (R.F.); daniel@ dsr.inpe.br (D.A.); mello@dsr.inpe.br (M.M.)

* Author to whom correspondence should be addressed; E-Mail: adami@ dsr.inpe.br (M.A.); Tel.: +5512-3208-6425; Fax: +55-12-3208-6488

Received: / Accepted: / Published:

\begin{abstract}
Mitigation of global carbon emissions, to prevent global warming potential, using biofuels is highly dependent on direct and indirect land use change (LUC). There are still several uncertainties about how to assess the indirect LUC impacts of biofuels. However, direct LUC (dLUC) can be evaluated using remote sensing (RS). The present work aims at quantifying the dLUC which occurred during the recent sugarcane expansion for ethanol and sugar production concentrated in the South-Central region of Brazil. This region has a favorable climate for rain-fed sugarcane production, a great potential for agriculture expansion without deforestation, and it is currently responsible for almost $90 \%$ of Brazilian's sugarcane production. Yearly monitoring from 2003 to 2010 using Landsat type imagery has shown that the sugarcane crop expanded during this period on more than 4.3 million hectares in the South-Central region. To evaluate the dLUC in response to the recent expanded sugarcane area, we used both Landsat images and MODIS time series transformed to the two-band enhanced vegetation index (EVI2), acquired from 2000 to 2009. An available Landsat based sugarcane map was re-sampled to a pixel size of $250 \times 250 \mathrm{~m}$ to be compatible with the spatial resolution of the MODIS images. One percent of the pure pixels were systematically sampled covering 1,046 pixels. Each of these pixels was carefully analyzed using a specially developed web tool to visualize the entire MODIS time series
\end{abstract}


overlaid with several Landsat images acquired at key periods in order to correctly identify the land use prior to the conversion to sugarcane. Considering 2000 as reference year for the dLUC evaluation, it was observed that: $69.8 \%$ of the sugarcane crop expanded on pasture land; $26.2 \%$ expanded on annual crops; $0.6 \%$ expanded on forest; while $3.5 \%$ was already sugarcane land, but under crop rotation. It was interesting to notice that $35 \%$ of the pasture land in 2000, eventually converted to sugarcane, was firstly converted to annual crops. This practice is commonly adopted for one or two years on degraded pasture land to improve the soil physic-chemical characteristics. It was also observed that the $0.6 \%$ of forest changed to sugarcane had previously been changed to pasture. The results clearly show that the dLUC observed during the recent sugarcane expansion for ethanol and sugar production in the South-Central region of Brazil has been occurring on more than $99 \%$ of either pasture or agriculture land. The indirect impacts of LUC have to be considered carefully, especially for the Brazilian case, due to the enormous amount of pasture land that has been released and will continue to be released for other land uses, particularly for agriculture, in response to the growing livestock production efficiency.

Keywords: LUC, biofuels, monitoring, MODIS.

\section{Introduction}

The use of biofuels to mitigate greenhouse gases (GHG) emissions and consequently prevent the global warming potential has been widely discussed [1]. The production of biofuel from sugarcane is well established in Brazil [2] and presents a great potential to mitigate GHG due to its high efficiency [3-5]. The growing demand of sugarcane for ethanol production, especially after 2003 with the advent of the flex cars in Brazil, caused a rapid expansion of this crop during the last years [6]. However, several discussions on the sustainable sugarcane production and its actual potential to mitigate GHG has been reported in the literature [7-8].

The direct land use change (dLUC) from pasture or other agricultural crops to sugarcane can contribute to local climate cooling [9]. With regard to food security, [10] discussed that the reduction of pasture land as a consequence of sugarcane expansion can be compensated by increasing the efficiency of livestock production. Furthermore, [11] concluded that the recent food price increase is not correlated to the increased demand of biofuels.

For [12] the potential benefits of biofuels to reduce carbon emissions are highly dependent on direct and indirect LUC triggered by the expansions of biocrops. [13] pointed out that crop management practices have a significant impact on carbon emissions as was also reported by [14] and [15], specifically for the sugarcane case. The indirect LUC (iLUC) impacts of the sugarcane expansion have been reported in the literature (e.g. $[13,16])$, but present many uncertainties in its evaluation. However, the dLUC impacts can be accurately quantified by using remote sensing satellite images [17].

These images are acquired by sensors on board of satellites and present different characteristics, especially in terms of its spatial and temporal resolutions. Several countries that own remote sensing satellites have recently adopted a policy to freely distribute these images through the Internet. This policy has dramatically increased the number of users and also the applications in the field of Earth 
observation, that otherwise would not have been possible due to the often prohibitive cost of the remote sensing images for environmental monitoring applications. Examples of countries that have adopted this policy are the USA, that since 2000 has freely been distributing images from the MODIS sensor on board of Terra and Aqua satellites for the entire terrestrial globe; and Brazil that in 2006 started to deliver through the Internet images from the CBERS (China-Brazil Earth Resource Satellite) and Landsat satellites over its own territory. Considering the enormous amount of freely available remote sensing images; the huge area of the South-central region of Brazil where sugarcane has rapidly expanded over the last decade; and the complexity of the aspects involved in the monitoring of LUC, this work aims at using satellite images from sensors with different spatial and temporal resolutions available on the Internet in order to quantify the dLUC observed during the first decade of the XXI century which was triggered by the increased demand of sugarcane for ethanol production.

\section{Materials and Methods}

\subsection{Study area}

The study area comprises the South-central region of Brazil (Goiás - GO; Mato Grosso - MT; Mato Grosso do Sul - MS; Minas Gerais - MG; Paraná - PR and São Paulo - SP states) currently responsible for $90 \%$ of the sugarcane production for sugar and ethanol in Brazil. With the beginning of the production of flex cars by the Brazilian automobile industry in 2003 a substantial increase in the amount of sugarcane area started to be observed in this region, moving from 4.3 million hectares in 2003 to 8.6 million hectares in 2011 (http://www.dsr.inpe.br/laf/canasat/). However, this increase could have been even bigger had it not been for the 2008 world crises which inhibited several new investments in the sucro-energy sector so the growth rate of new sugarcane plantations was significantly reduced as illustrated in Figure 1 . On the other hand, the demand for ethanol in the internal market, and the demand for sugar in the external market continued to increase independently of the world crises resulting in a shortage of ethanol since 2010 to supply the Brazilian market. It is estimated that this shortage will only be solved by 2013 through a new boom of sugarcane plantation that should start in 2011. 
Figure 1. Expansion of Sugarcane in South-Central Brazil from 2005/06 to 2010/11.

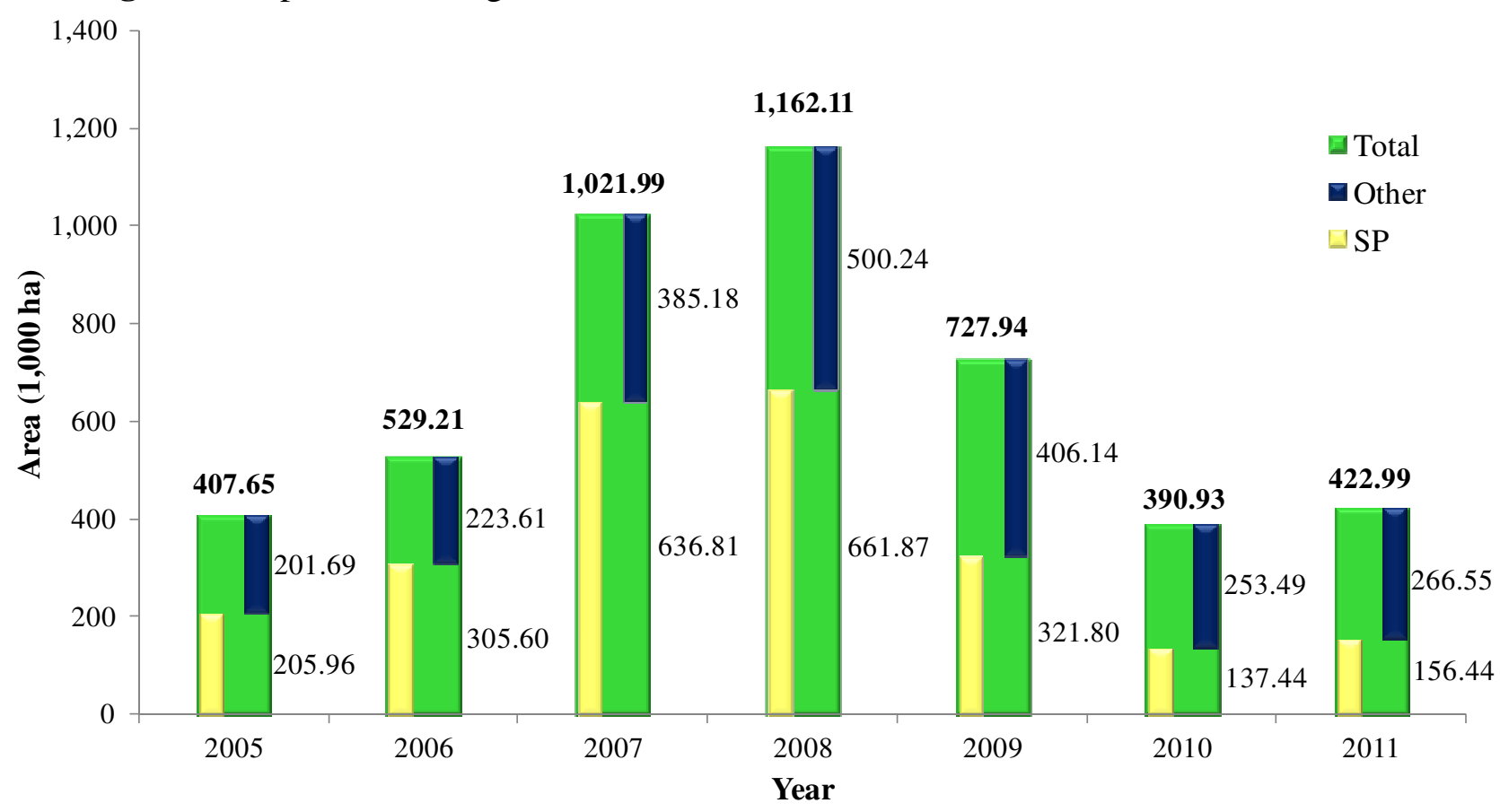

In the South-central region of Brazil, São Paulo state has long been the major sugarcane producer, but recently other states such as Mato Grosso do Sul and Goiás have significantly been increasing their sugarcane area. Furthermore, these states have huge available areas for agricultural use; while São Paulo state is already covered with $21.7 \%$ of its territory with sugarcane and its options for expansion have become more and more limited. In 2005 São Paulo state was responsible for $72.6 \%$ of the sugarcane area in the South-central region while in 2011 its share went down to $62.3 \%$ due to the sugarcane area increase in other states of the region. Figure 2 illustrates sugarcane area mapped with the use of remote sensing images in $2011[6,18]$. 
Figure 2. Study area emphasizing the expanded sugarcane area from crop year 2005/06 to 2010/11 in the South-central region of Brazil. The states of Rio de Janeiro, Espírito Santo, Santa Catarina and Rio Grande do Sul are also part of this region; however, sugarcane expansion was not significant in these

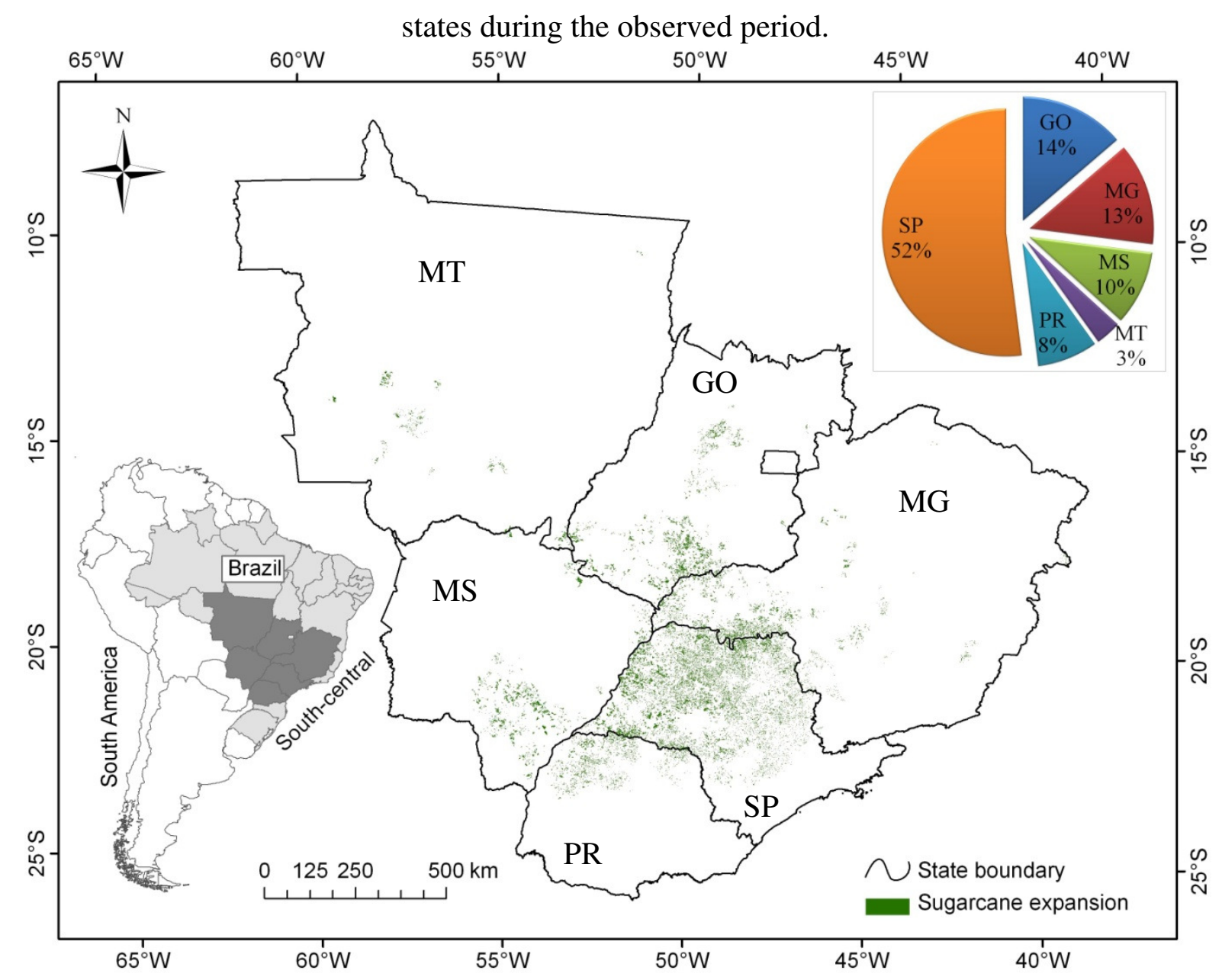

\subsection{Materials}

The materials utilized in this study were: I) an available sugarcane map of the expanded sugarcane areas for crop years 2005/06 to 2010/11 for São Paulo state and crop years 2007/08 to 2010/11 for the other sugarcane producing states in the South-central region (Figure 2); II) 1,184 Landsat satellite images acquired between 2000 and 2009 over the sugarcane areas in the South-central region (50 different path/row); III) time series of MODIS (Moderate Resolution Imaging Spectroradiometer) from the Terra satellite for the period of 2000 to 2010 available at https://www.dsr.inpe.br/laf/series/.

\subsection{Methods}

The analysis of the dLUC dynamic from 2000 to 2009 in the South-central region was carried out considering the sugarcane expansion observed for São Paulo state from crop years 2005/06 to 2010/11; and for the other states of the region from crop years 2007/08 to 2010/11 since the major expansions by state were observed during these crop years (Figure 1). The original sugarcane map of the sugarcane expansion areas was available in vector format, and was re-sampled and converted to raster format with spatial resolution of $250 \times 250 \mathrm{~m}$ in order to be compatible with the MODIS image resolution. This conversion resulted in a map with 104,583 elements $(\mathrm{N})$ of "pure pixels" of sugarcane. 
Based on these elements a systematic sampling was performed [19] selecting a sample (1\%) with 1,046 elements (n). The first element was randomly selected and served as reference for the remaining elements, by adding 100 to each new selected element, until the total number of elements was selected. A systematic sampling assures that the entire geographic region will be represented and that the amount of elements will be selected considering its spatial distribution.

The objective of the sampling is to estimate the area proportion (eq. 1) of each land use class prior to the sugarcane crop:

$$
\widehat{p_{c}}=\frac{1}{n} \sum_{i=1}^{n} y_{i}
$$

where y represents the sample whose identifier varies from $i$ to $n, y_{i}$ will be one if it belongs to class $c$, otherwise it will be zero; $\widehat{p_{c}}$ is the proportion of samples that belong to class $c$. The expansion of the area for each class $\widehat{a_{c}}$ will be obtained by $\widehat{a_{c}}=N \widehat{p_{c}}$

The variance of the estimates for each class $\left(v_{c}\right)$ was estimated by eq. 2

$$
v_{c}=n \widehat{p_{c}} \widehat{q_{c}} \frac{N-n}{N-1}
$$

Where $\widehat{\mathrm{q}_{\mathrm{c}}}=1-\widehat{\mathrm{p}_{\mathrm{c}}}$; whose confidence interval for each class $\left(i c_{c}\right)$ is obtained by eq. 3

$$
\mathrm{ic}_{\mathrm{c}}= \pm \mathrm{Z} \alpha / 2 \sqrt{\mathrm{v}_{\mathrm{c}}}+\frac{1}{2 \mathrm{n}}
$$

where $\mathrm{Z}$ is the critical value of the standardized normal probability density function, in terms of the confidence interval $(\alpha / 2)$

The classification of the land use prior to the sugarcane crop was carried out using visual image interpretation combining the use of the relatively high spatial resolution of Landsat images with the high temporal resolution of MODIS images. A web tool, illustrated in Figure 3, was specially developed to integrate the 1,046 sampled elements with Landsat images and MODIS time series. This allowed the interpreter to assign year by year, from 2000 to 2009, each one of the elements to one of the following classes: Pasture, Annual crop, Citrus, Reforestation, Forest and Sugarcane. 
Figure 3. (a) Virtual Globe integrated with Landsat color composite images. The small red square refers to the MODIS pixel presented in the graph. The area defined in black indicates the expanded sugarcane area. (b) MODIS EVI2 time series from the indicated pixel. (c) Classification area

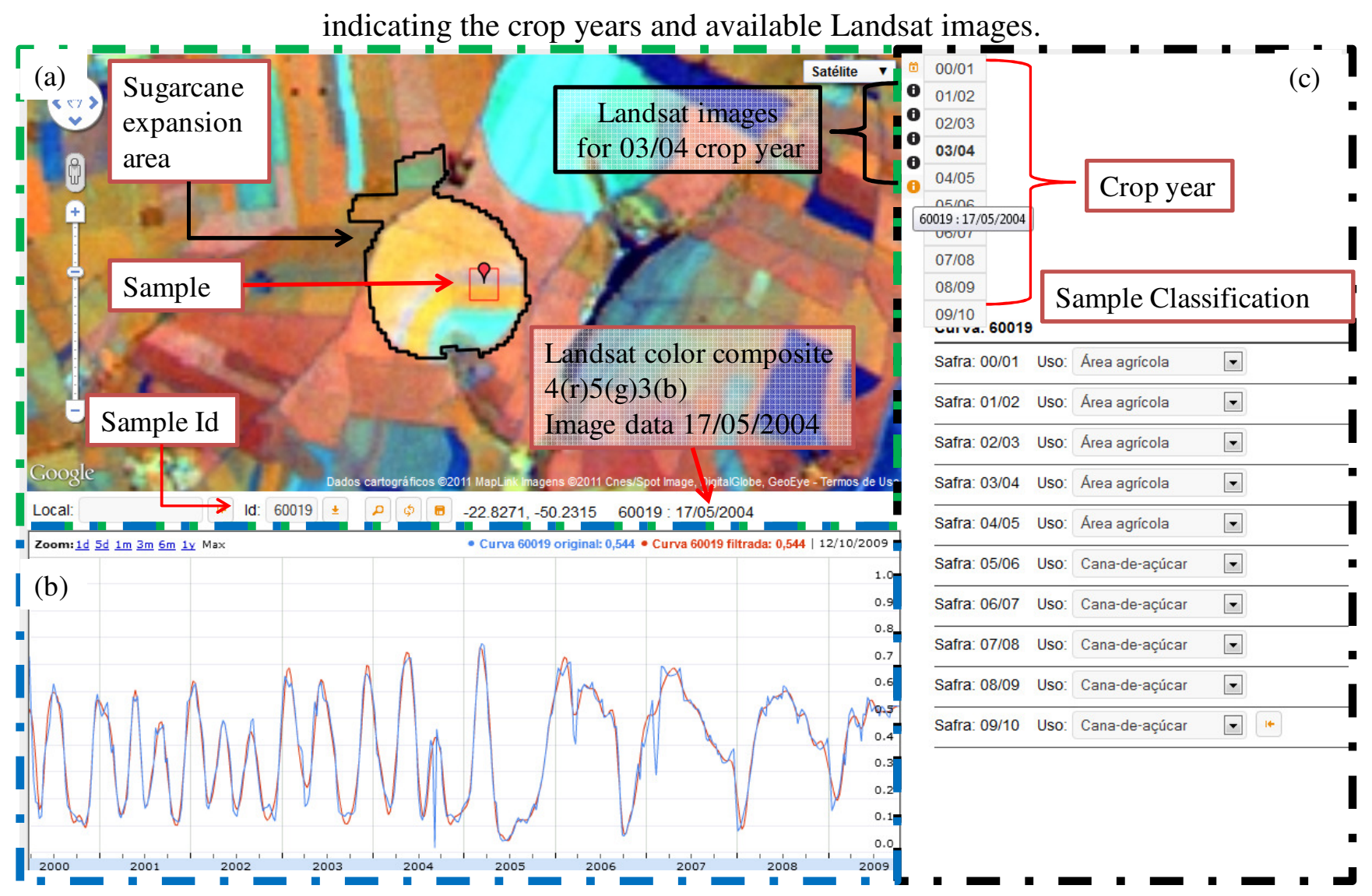

The Landsat images available on the web tool were acquired yearly from 2000 to 2009 some time during the rainy season (October through March) and some time during the dry season (May through August). To interpret each element a piece of the Landsat image was selected covering an area of $15 \mathrm{x}$ $15 \mathrm{~km}$ around the selected element as illustrated in Figure 3.

The MODIS time series used in the web tool was constructed based on data from the collection 5 of the MOD09 product ( 8 day composition) available at the portal of the Warehouse Inventory Search Tool WIST NASA (https://wist.echo.nasa.gov). The pixel selection process for the MOD09 product takes into account the parameters obtained from the MOD35 and MOD04 products in order to select cloud free pixels with lowest view angle. Information of the Quality Assessment (QA) product for the daily acquired images from the MOD09GHK product are also used in this process [20]. Even though this selection process eliminates most of the unwanted information present in the raw MODIS data, it is still noisy, especially for visualization purpose in the form of graphs. Therefore, data from the MOD09 product were further processed following the method proposed by [21] using two additional filters to improve the visual quality of the time series presented in the form of graphs. The first filtering consists of withdrawing pixels with both view angle greater than $30^{\circ}$ and spectral reflectance greater than $10 \%$ in band 3 (blue), as suggested by [22]. Afterwards, the time series were linearly interpolated at daily scale using the MODIS product day-of-year, as suggested by [23]. The second additional filtration proposed by [23] uses the mother wavelet DB8 [24]. 
Eventually, the filtered data, coming from the MODIS images acquired from 2000 to 2009 over the entire study area, were used to calculate the vegetation index named EVI2 (Two Band Enhanced Vegetation Index - [25]) that was the ultimate representation of the MODIS images in the time series presented in the web tool (Figure 3). The time series graphs in blue and red color, presented in Figure 3 , are respectively from the first (without wavelet) and second (with wavelet) additional filtration proposed by [21]. The two time series are quite similar and the interpreter could choose which one provides the best information to classify the land use for the selected elements.

It is worth mentioning that, on the web tool, the MODIS EVI2 time series are only available for each selected element of $250 \times 250 \mathrm{~m}$ to be classified since there is no need to spatially contextualize those elements, but rather observe the vegetation index (EVI2) behavior over time which should help to understand the LUC history of each particular element. However, for the Landsat images it is fundamental to spatially contextualize each selected element so that the image can actually help to correctly classify the LUC; therefore, each selected element was surrounded by an area of $15 \mathrm{x} 15 \mathrm{~km}$. After the classification of the 1,046 selected elements by the interpreters, the conversion metrics were obtained using descriptive statistics.

\section{Results and discussion}

Figure 4 presents the result of the dLUC dynamic analysis observed in the South-central region of Brazil during the first decade of the XXI century in response to the recent sugarcane expansion that was mainly triggered by the increased demand of sugarcane to produce ethanol. From the total sugarcane area expanded in São Paulo state since 2005 and in the rest of the South-central region since 2007 , it can be noticed that in the year 2000, 69.8\% $( \pm 2.8 \%)$ of this area was Pasture and $24.9 \%$ $( \pm 2.6 \%)$ was Annual crop which together account for $94.7 \%$ of the dLUC due to sugarcane. An area equivalent to $3.5 \%( \pm 1.1 \%)$ was already under sugarcane cultivation, back in 2000 , which correspond to the sugarcane fields under renovation in 2005 in São Paulo and in 2007 for the remaining states. Still in regard to the year $2000,1.3 \%( \pm 0.07 \%)$ of sugarcane expanded over Citrus. The dLUC from Citrus to sugarcane was only observed in São Paulo state once no significant citrus plantations are found outside São Paulo state within areas under the influence of sugarcane plantation. Finally, $0.6 \%$ $( \pm 0.05 \%)$ of the sugarcane expanded over areas that were Forest in 2000 corresponding to an area of 16.8 thousand ha. In a survey carried out by [26] at 343 sugar and ethanol plants to evaluate the dLUC of expanded sugarcane areas in crop year 2007/08 observed that $66 \%$ of sugarcane expanded on pasture land and $29 \%$ on annual or perennial crops, and the other 5\% came from other classes not specified in the paper; however, the base line year to be used as reference for the dLUC evaluation was not reported. [17] used Landsat images to evaluate the dLUC of sugarcane expansion in crop years 2006/07 and 2008/09. They observed that 51\% expanded on Pasture; $48 \%$ on annual or perennial crops and $1 \%$ on cultivated or natural forest.

Analyzing the results of the dLUC dynamic presented in Figure 4, one can notice that the Annual crop area in 2000 slightly increased between 2001 and 2006 indicating that part of the Pasture land converted to sugarcane was firstly converted to Annual crop. This is a commonly adopted management practice to improve the physic-chemical soil characteristics of the degraded pasture land [27]. Figure 4 refers to the residual Annual crop area $(\sim 1 \%)$ observed in 2008 and 2009. This area is from the 
expanded sugarcane fields that were either under crop rotation or for some reason converted to Annual crop.

Figure 4. The direct land use change dynamic for sugarcane expansion in the South-central region of Brazil over the period of 2000 to 2009.

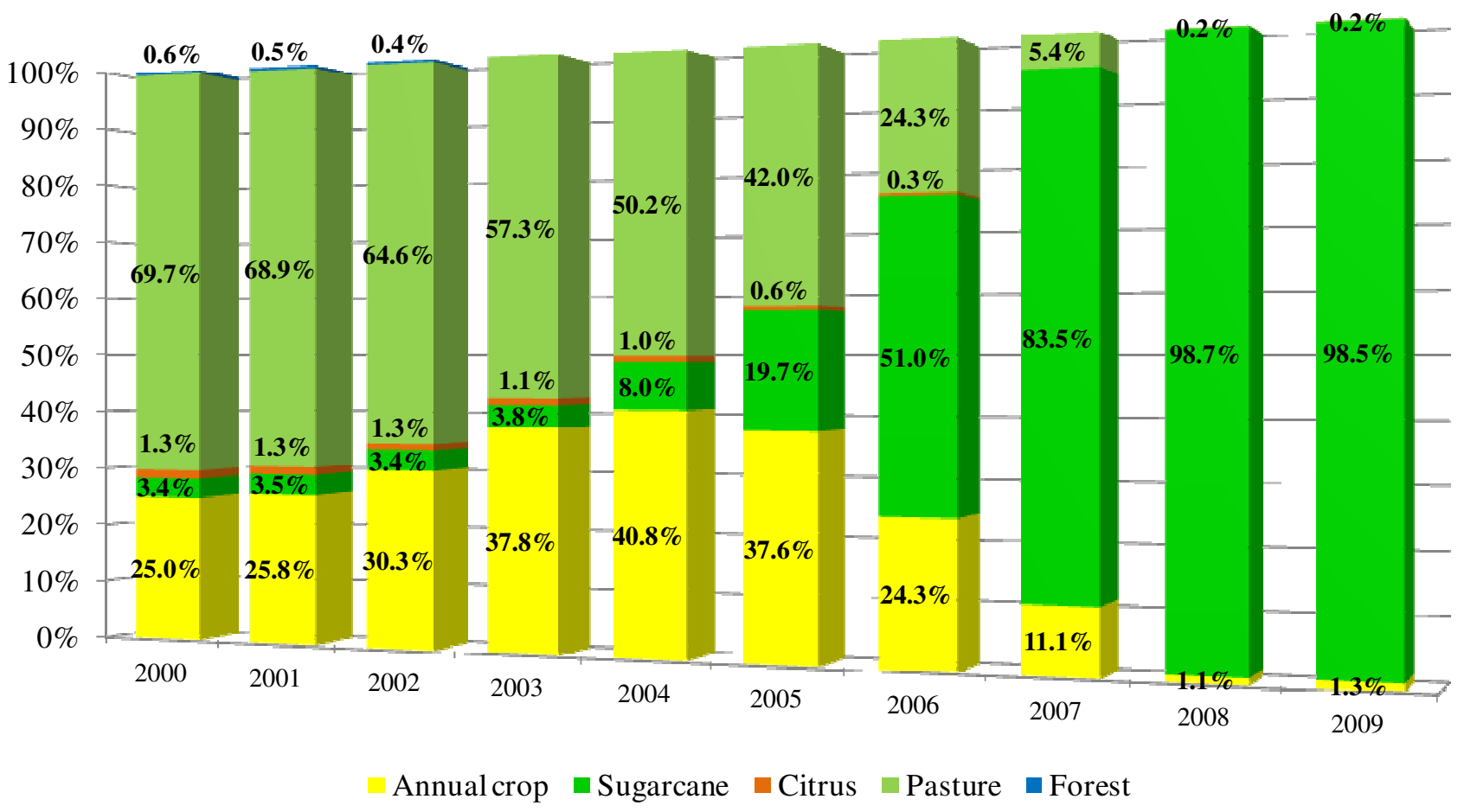

Figure 5 shows that from the total Pasture land in 2000, 65\% was directly converted to sugarcane, and $35 \%$ was firstly converted to Annual crop explaining the gradual increment of this class between 2001 and 2006 (Figure 4). Figure 5 also shows that the Forest class was initially converted to Pasture and later to sugarcane; while the conversion of both Annual crop and Citrus to sugarcane was direct.

Figure 5. The conversion process of the different land use classes to sugarcane. The values inside the boxes represent the area estimates that were generated from the sampling procedure for the year of 2000 and eventually converted to sugarcane by 2010 . 


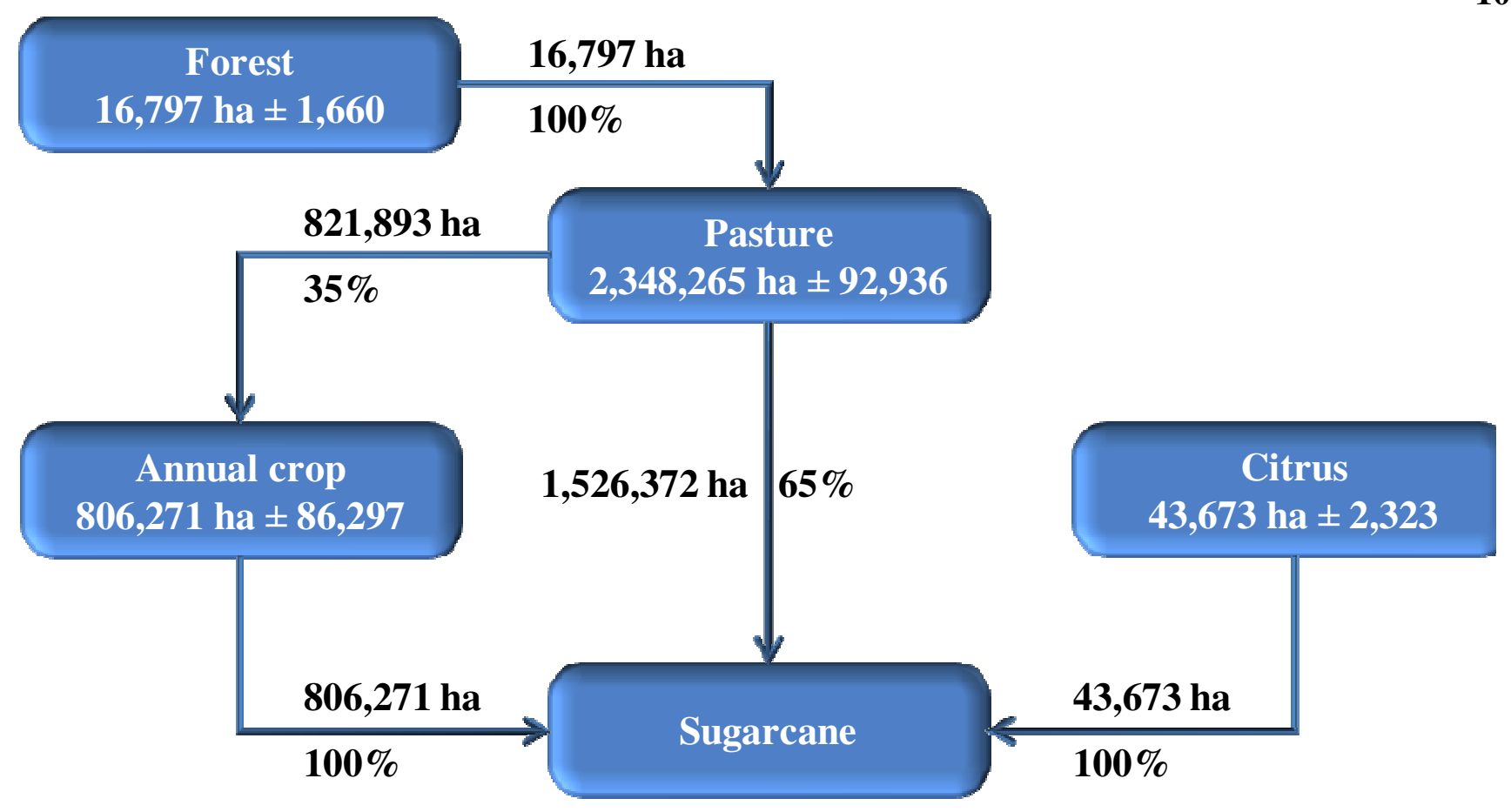

These numbers agree with [16] in regard to the small impact of sugarcane expansion on deforestation; however, they disagree with [28] in regard to the significant impact of sugarcane on biodiversity, since more than $99 \%$ of the recent expanded sugarcane area was on land occupied prior to 2000 with either pasture or agriculture. Considering that the majority of the pasture land in Brazil is somehow degraded [29], then the major observed LUC from pasture to sugarcane for ethanol production might have an even more significant contribution not only in the mitigation of GHG according to the study of [30] but also in the cooling of local climate according to the conclusion of [9].

The assessment of iLUC on sugarcane expansion is not simple to analyze. The dLUC analysis showed that sugarcane expanded on either pasture or agricultural land. Therefore, it is expected that the reduced pasture land will either reduce the cattle herd or induce deforestation for new land availability. However, for the Brazilian case, the intensification of pasture land use due to increased livestock efficiency has released much land for crop production, and this will continue during the next decades, so that no further deforestation should be needed to accommodate the demand of new land for either food or biofuel production [31-32]. For example, in São Paulo state the cattle herd carrying capacity went from 1.00 head per hectare in 1975 to 1.85 heads per hectare in 2006, and although the pasture land was significantly reduced by 4.4 million hectares the cattle herd increased by 1.4 million heads [33]. Also, the South-central region experienced both a loss of 24.1 million hectares and an increase of 45.3 million heads of cattle just by increasing the carrying capacity from 0.58 to 1.23 heads per hectare from 1975 to 2006 [33].

Similarly, the Brazilian grain production has continuously grown over the last 36 years at an annual rate of $3.8 \%$, which can be attributed to the annual growth rate of crop yield $(2.5 \%)$ and also to the increase in cropped area by an annual rate of $1.3 \%$ [34]. It is expected that under a competitive economy the productivity gains should continue over time; therefore, they have to be considered in iLUC modeling. For example, if the current growth rate of Brazilian's grain production continues to be the same for the next 17 years it will represent a $50 \%$ increase in grain production which was not 
accounted for by the iLUC effects modeled by [16]. Another relevant but difficult aspect to consider in iLUC modeling effects of biofuels is related to environmental protection measures imposed by the consumer market, such as the Soy Moratorium [35], not to mention the large number of certification initiatives that are extremely concerned with the effects of biofuels on LUC.

\section{Conclusions}

The remote sensing satellite images at different spatial and temporal resolutions were useful to evaluate the direct land use change observed during the last decade triggered by the increased demand of sugarcane for ethanol production in the South-Central region of Brazil.

More than $99 \%$ of the recent sugarcane expansion for ethanol and sugar production was either on pasture or agricultural land. The indirect impacts of LUC have to be considered carefully, especially for the Brazilian case, due to the enormous amount of pasture land that has been released and will continue to be released for other land uses, particularly for agriculture, in response to the growing livestock production efficiency.

\section{Acknowledgments}

The authors would like to thank the team from Laboratory of Remote Sensing in Agriculture and Forestry - LAF for their valuable contributions to this work.

\section{Conflict of Interest}

The authors declare no conflict of interest.

\section{References and Notes}

1. Zuurbier, P.J.P.; Vooren, J.v.d. Sugarcane ethanol : contributions to climate change mitigation and the environment. Wageningen Academic Publishers: Wageningen, Netherlands :, 2008.

2. Goldemberg, J. Ethanol for a Sustainable Energy Future. Science 2007, 315, 808-810.

3. Coelho, S.T.; Goldemberg, J.; Lucon, O.; Guardabassi, P. Brazilian sugarcane ethanol: lessons learned. Energy for Sustainable Development 2006, 10, 26-39.

4. Nass, L.L.; Pereira, P.A.A.; Ellis, D. Biofuels in Brazil: An Overview. Crop Sci. 2007, 47, 2228-2237.

5. Hira, A.; Oliveira, L.G. No substitute for oil? How Brazil developed its ethanol industry. Energy Policy 2009, 37, 2450-2456.

6. Rudorff, B.F.T.; Aguiar, D.A.; Silva, W.F.; Sugawara, L.M.; Adami, M.; Moreira, M.A. Studies on the Rapid Expansion of Sugarcane for Ethanol Production in São Paulo State (Brazil) Using Landsat Data. Remote Sensing 2010, 2, 1057-1076.

7. Goldemberg, J.; Coelho, S.T.; Guardabassi, P. The sustainability of ethanol production from sugarcane. Energy Policy 2008, 36, 2086-2097.

8. Smeets, E.; Junginger, M.; Faaij, A.; Walter, A.; Dolzan, P.; Turkenburg, W. The sustainability of Brazilian ethanol-An assessment of the possibilities of certified production. Biomass and Bioenergy 2008, 32, 781-813.

9. Loarie, S.R.; Lobell, D.B.; Asner, G.P.; Mu, Q.; Field, C.B. Direct impacts on local climate of sugar-cane expansion in Brazil. Nature Clim. Change 2011, 1, 105-109. 
10. Martinelli, L.A.; Garrett, R.; Ferraz, S.; Naylor, R. Sugar and ethanol production as a rural development strategy in Brazil: Evidence from the state of São Paulo. Agricultural Systems 2011, In Press, Corrected Proof.

11. Mueller, S.A.; Anderson, J.E.; Wallington, T.J. Impact of biofuel production and other supply and demand factors on food price increases in 2008. Biomass and Bioenergy 2011, 35, 1623 1632.

12. Hill, J.; Polasky, S.; Nelson, E.; Tilman, D.; Huo, H.; Ludwig, L.; Neumann, J.; Zheng, H.; Bonta, D. Climate change and health costs of air emissions from biofuels and gasoline. Proceedings of the National Academy of Sciences 2009, 106, 2077-2082.

13. Kim, H.; Kim, S.; Dale, B.E. Biofuels, Land Use Change, and Greenhouse Gas Emissions: Some Unexplored Variables. Environmental Science \& Technology 2009, 43, 961-967.

14. Macedo, I.C.; Seabra, J.E.A.; Silva, J.E.A.R. Green house gases emissions in the production and use of ethanol from sugarcane in Brazil: The 2005/2006 averages and a prediction for 2020. Biomass and Bioenergy 2008, 32, 582-595.

15. Figueiredo, E.B.; La Scala Jr, N. Greenhouse gas balance due to the conversion of sugarcane areas from burned to green harvest in Brazil. Agriculture, Ecosystems \&amp; Environment 2011, 141, 77-85.

16. Lapola, D.M.; Schaldach, R.; Alcamo, J.; Bondeau, A.; Koch, J.; Koelking, C.; Priess, J.A. Indirect land-use changes can overcome carbon savings from biofuels in Brazil. Proceedings of the National Academy of Sciences of the United States of America 2009, 107, 3388-3393.

17. Nassar, A.M.; Rudorff, B.F.T.; Antoniazzi, L.B.; Aguiar, D.A.; Bacchi, M.R.P.; Adami, M. Prospects of the sugarcane expansion in Brazil: impacts on direct and indirect land use changes. In Sugarcane ethanol - Contributions to climate change mitigation and the environment, 1 ed.; Zuurbier, P.; van De Vooren, J., Eds.; Wageningen Academic Publishers: Wageningen, 2008; pp 63-92.

18. Silva, W.F.; Aguiar, D.A.; Rudorff, B.F.T.; Sugawara, L.M. In CANASAT Project: Monitoring of the sugarcane cultivation area in south central Brazil, 100 Years ISPRS, Vienna - Austria, July 57, 2010, 2010; Wagner, W.; Székely, B., Eds. ISPRS: Vienna - Austria, 2010; pp 535-540.

19. Cochran, W.G. Sampling techniques John Wiley New York \& Sons, Inc., 1977; p 428.

20. Vermote, E.F.; Vermeulen, A. Atmospheric correction algorithm: spectral reflectances (MOD09). AlgorithmTheoretical Background. In National Aeronautics and Space Administration: 1999; p 107.

21. Freitas, R.M.d.; Arai, E.; Adami, M.; Ferreira, A.S.; Sato, F.Y.; Shimabukuro, Y.E.; Rosa, R.R.; Anderson, L.O.; Rudorff, B.F.T. Virtual laboratory of remote sensing time series: visualization of MODIS EVI2 data set over South America JCIS - Journal of Computational Interdisciplinary Sciences 2011, 2, 57-68.

22. Sakamoto, T.; Yokozawa, M.; Toritani, H.; Shibayama, M.; Ishitsuka, N.; Ohno, H. A crop phenology detection method using time-series MODIS data. Remote Sensing of Environment 2005, 96, 366-374.

23. Thayn, J.B.; Price, K.P. Julian dates and introduced temporal error in remote sensing vegetation phenology studies. International Journal of Remote Sensing 2008, 29, 6045 - 6049.

24. Daubechies, I. Ten lectures on wavelets. Society for Industrial and Applied Mathematics: Philadelphia, USA, 1992; p 352.

25. Jiang, Z.; Huete, A.R.; Didan, K.; Miura, T. Development of a two-band enhanced vegetation index without a blue band. Remote Sensing of Environment 2008, 112, 3833-3845.

26. CONAB Perfil do Setor de Açúcar e Álcool no Brasil; Companhia Nacional de Abastecimento: Brasilia, 2008; p 76.

27. Boddey, R.M.; Xavier, D.F.; Alves, B.J.R.; Urquiaga, S. Brazilian Agriculture: The Transition to Sustainability. Journal of Crop Production 2003, 9, 593-621.

28. Naylor, B.Y.R.L.; Liska, A.J.; Burke, M.B.; Falcon, W.P.; Gaskell, J.C.; Rozelle, S.D.; Cassman, K.G. The Ripple Efect. Biofuels, Food Security, and the Environment. Environment 2007, 49, 30-43. 
29. Costa, F.P.; Rehman, T. Exploring the link between farmers' objectives and the phenomenon of pasture degradation in the beef production systems of Central Brazil. Agricultural Systems 1999, 61, 135-146.

30. Searchinger, T.; Heimlich, R.; Houghton, R.A.; Dong, F.; Elobeid, A.; Fabiosa, J.; Tokgoz, S.; Hayes, D.; Yu, T.-H. Use of U.S. croplands for biofuels increases greenhouse gases through emissions from land-use change. Science 2008, 319, 1238-1240.

31. Nassar, A.M. Brazil As An Economic Superpower. In Brazil As An Economic Superpower? Understanding Brazil's Changing Role In The Global Economy, 1 ed.; Brainard, L.; MartinezDiaz, L., Eds.; Brookings Institution: Washington, D. C., 2009; pp 55-80.

32. Macedo, L.O.B. MODERNIZAÇÃO DA PECUÁRIA DE CORTE BOVINA NO BRASIL E A IMPORTÂNCIA DO CRÉDITO RURAL. Informações Econômicas 2006, 36, 83-95.

33. IBGE, I.B.d.G.e.E. Sistema IBGE de Recuperação Automática. In http://www.sidra.ibge.gov.brl, 2011.

34. CONAB Séries históricas relativas às safras 1976/77 a 2009/2010 de área plantada, produtividade e produção. In CONAB, Ed. Brasilia, 2011.

35. Rudorff, B.F.T.; Adami, M.; Aguiar, D.A.; Moreira, M.A.; Mello, M.P.; Fabiani, L.; Amaral, D.F.; Pires, B.M. The Soy Moratorium in the Amazon Biome Monitored by Remote Sensing Images. Remote Sensing 2011, 3, 185-202.

(C) 2011 by the authors; licensee MDPI, Basel, Switzerland. This article is an open access article distributed under the terms and conditions of the Creative Commons Attribution license (http://creativecommons.org/licenses/by/3.0/). 